\title{
Think of Scientific Research Management in Scientific Research Institutes in China
}

\author{
Li Rui ${ }^{1,2}$, Lv Liemin ${ }^{1,2}$, Zhu Yongqin ${ }^{1}$ \\ ${ }^{1}$ Anhui and Huaihe River Institute of Hydraulic Research, Anhui Bengbu, China \\ ${ }^{2}$ Anhui Province Key Laboratory of Water Conservancy and Water Resources, Anhui Bengbu, China \\ Email address: \\ Lrlr336@163.com (Li Rui),1lm@ahwrri.org.com (Lv Liemi), zyq@ ahwrri.org.com (Zhu Yongqin)
}

\section{To cite this article:}

Li Rui, Lv Liemin, Zhu Yongqin. Think of Scientific Research Management in Scientific Research Institutes. International Journal of Economics, Finance and Management Sciences. Vol. 3, No. 5, 2015, pp. 654-656. doi: 10.11648/j.ijefm.20150305.43

\begin{abstract}
The scientific research is a process in which the researcher apply the scientific knowledge on the practice, and is a link between theory and practice as well. Being the main carrier, the research institutes of some scientific research institution has functions of developing science technology and servicing for society. Every institute has own administration section, which decides whether administration service level update and scientific research achievement application. In this paper, the author discusses the current administration section function based on her work experience, and on the further provides some suggestions to enhance the administration service level in scientific research institutions.
\end{abstract}

Keywords: Scientific Research, Management, System, Incentive

\section{关于中国科研院所科研管理工作的一些思考}

李瑞 ${ }^{1,2}$, 吕列民 ${ }^{1,2}$, 朱永勤 ${ }^{1}$

${ }^{1}$ 安徽省水利部淮河水利委员会水利科学研究院, 安徽蚌埠, 中国

${ }^{2}$ 水利水资源安徽省重点实验室, 安徽蚌埠, 中国

邮箱

Lr1r336@163. com(李瑞)，11m@ahwrri.org. com(吕列民）ｚyq@ahwrri.org.com(朱永勤)

摘要: 科学研究是将研究者所学的知识运用到实际问题中, 连接理论和实践的一个纽带和桥梁。作为科研机构的科研 院所, 承担着发展科学技术和服务社会的职能。而科研院所的科研管理工作是科研院所中极其重要的一部分, 科研管 理工作开展的成功与否, 直接影响到科研水平的长足提高和科研成果的有效转化。笔者根据自己的工作经验就中国科 研院所的科研管理工作进行分析, 旨在能够提出一点提高科研院所科研管理水平的浅见。

关键词: 科研, 管理, 制度, 激励

\section{1. 引言}

管理是社会发展到一定阶段的产物, 它利用组织及其 成员赋予的权力为组织及其成员的利益服务, 其实质与服 务是统一的。科研管理是管理的一大分支, 服务是科研管 理职能中最重要的组成部分, 从本质上讲, 科研管理就是 为科研服务。随着社会的发展与生产力水平的提高, 管理 出效益、管理出成果的观念越来越被人们所认识、接受。
本文是笔者根据自己的工作经验, 就科研院所的科研管理 工作进行分析, 旨在能够提出一点提高科研院所科研管理 水平的浅见。

\section{2. 科研院所科研管理的范围}

科研院所科研管理主要是对科研项目的管理, 科研项 目管理的工作包括科研项目申请通知的发布、项目材料的 
收集、管理、整理等, 量多且繁杂。下面想简单分级别统 计一下科研项目的范围, 以期能对科研项目有个简单的了 解。

(1) 中国国家级科研项目: 包括973计划、863计划、 科技支撑项目及自然科学基金、国家农业科技成果转化资 金项目等科技部下达的项目。

（2）中国部委级科研项目：包括公益性行业科研专 项项目、科技推广计划项目、“948”项目等国家所属部 (委、局、办) 非科技主管部门下达的科研项目等。

（3）中国省级科研项目：包括省重大科技专项、省 科技攻关计划项目、省自然科学基金项目、省优秀青年科 技基金项目、省年度重点科研项目、省软科学研究项目、 省农业科技成果转化资金项目、省公益性科研专项项目、 省国际科技合作计划项目等由省科技厅下达的项目。

（4）中国市厅级科研项目：包括省直属厅、市科技 管理部门下达的基础研究、重大技术问题研究、应用研究 等项目，省部所属厅（司、局）非科技主管部门下达的科 研项目, 市（厅、委）所属局（处、委、办）下达的基础 研究、重大技术问题研究、应用研究等项目。

（5）中国横向协作课题, 指其他单位委托或合作研 究, 经费由委托或合作单位资助, 成果由资助单位采用, 未列入中国国家和地方科研计划的研究项目。

(6) 其他研究课题。
纵观各个科研院所, 其所涉及到的科研项目类型大都 囊括在此。科研项目的管理也就是针对这些项目来开展的。

\section{3. 科研管理的方式方法}

一般科研项目应全面实行项目负责人制和项目合同 责任制相结合的制度。具体管理模式可以考虑管理部门 （科研管理处、财务处、科技信息中心）、业务部门和项 目组三级管理模式。就笔者所在的科研院所而言, 其各个 部门各司其责，具体分工如下:

(1) 科研管理处作为院科研管理的统一归口部门, 负责各类科研项目的信息发布、申报、实施、结题、验收、 鉴定和报奖等环节的组织、管理和监督。

（2）财务处负责对科研项目经费统一管理。

（3）科技信息中心综合档案室负责对科研项目档案 统一管理, 及后期的成果奖励办理。

（4）各业务所及项目负责人负责各自业务范围的科 研项目的申报、实施、结题、验收、鉴定和报奖等具体工 作, 并对所承担项目提供必要条件支持以及协调、督促工 作。

目前笔者所在单位的科研管理工作已经初显雏形, 但 是还未形成一个完善的系统, 如果按照系统设计, 则根据 使用对象，具体系统模块可安排如表1。

表1 中国科研院所科研管理系统模块表。

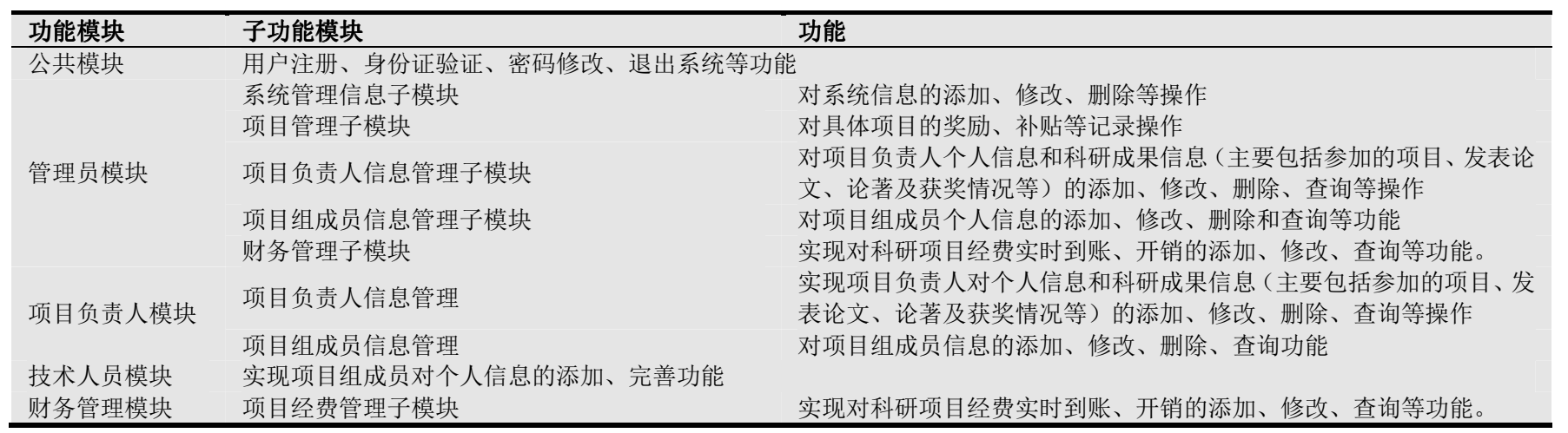

\section{4. 科研管理中存在的问题}

\section{1. 科研管理者服务意识不够}

（1）由于每个科研院所各部门间所涉及的专业不同, 而每个单位的科研管理者仅仅是二、三人，且专业素质和 水平参差不齐, 很多管理人员只是行政式的办公, 导致科 研管理工作难以有效开展。

（2）科研管理者仅仅将科研管理工作作为自己的本 职工作来完成, 没有将其与单位的发展定位相结合, 即没 有充分认识到科研管理的重要性, 难以提高服务意识, 无 法为科研人员的科研工作提供指导和协助服务。

\section{2. 科研管理制度不完善}

一般来说, 各个科研院所都会结合自身实际情况制定 相应的科研管理制度或者办法, 提出相应的科研项目申报、
进度管理、经费使用、课题验收的管理办法。但是, 科研 人员在研究过程中总会遇到新的问题。笔者在工作过程中 体会到, 科研管理过程中遇到的问题可以总结为以下几个 方面:

(1) 科研项目缺乏激励机制, 科研人员难以积极开 展科研活动。众所周知, 科研工作需要经费支撑。在项目 申报期间, 由于国家的总经费有控制, 造成最终下达的项 目经费会比原来申报时减少, 导致科研工作开展起来困难 重重。受政策和条件限制, 科研院所现在大多还都没有有 效的激励机制来调动科研人员的积极性。

(2) 科研经费使用存在问题, 这主要体现在科研经 费的使用难以按照预算执行, 监督工作也难以有效开展。 首先, 科研人员在科研过程中会遇到新问题, 造成科研项 目没有结题或验收之前经费就已经用完或者科研工作已 经结束, 但是科研经费仍有盈余, 这样容易造成科研经费 使用的不合理不科学, 对科研项目造成不良影响。其次, 
科研项目的技术管理和财务管理往往是分开的, 使得科研 管理的前、中、后期的监督难以有效开展。

（3）科研项目单位之间协作管理难以有效开展

作为一个科研机构, 其承接科研项目的数量和质量决 定着单位未来的发展空间和方向。一般国家和省部级项目 大多需要和协作单位共同完成, 各个单位分配的任务不同, 项目执行进度也不同, 项目承担单位各自有其不同的行政 管理体系和业务范围。项目工作任务分配后, 按照相关规 定, 项目经费也必须按时足额下发, 这就造成了项目主持 单位很难通过经济手段有效地控制工作进度和质量。在这 种工作体制下, 项目推进速度慢, 质量难以控制都成为了 很现实的问题。这样许多科研项目在验收时, 往往会出现 “木桶效应”, 因为其中的一个单位不过关, 影响了整个 项目的质量。

\section{5. 提高科研管理水平的对策}

\section{1. 树立服务意识}

科研管理者应该摒弃落后的管理思想, 转变观念, 树 立全心全意为广大科研人员服务的意识, 形成积极主动为 科研人员服务的作风。同时, 科研管理人员更应该加强综 合素质的提高, 掌握先进和科学的管理理念, 运用管理理 念解决具体问题。单位更需加强对科研管理人员的在职培 训, 提高业务熟练能力, 鼓励并支持管理人员对外交流与 学习等。

\section{2. 突出激励机制, 调动科研人员积极性}

科研出成绩与科研人员的积极性息息相关。因此，科 研院所应出台一系列的政策激励科研人员开展科研工作。 科研院所更应根据自身的情况出台相应的政策留住人才, 培养人才, 充分调动科研人员创新的积极主动性。同时对 于科技成果奖励出台更具有效果的奖励政策，包括资金、 职称、学习机会等, 对科研管理人员也要给予一定的激励 与奖励政策。

\section{3. 完善科研管理制度}

科研管理制度的完善需要从科研院所的实际出发, 积 极探索适合自身发展的方法。制定科研管理制度之时, 需 要借鉴相关兄弟单位的优秀管理经验, 同时, 也应该积极 与科研人员沟通交流, 听取他们的意见, 并将意见汇总, 组织相关部门人员进行研究, 制定相应的解决办法。充分 调动各部门的力量, 开展科研项目的前期、中期、后期的 项目进度检查和经费执行情况检查工作。制定政策加强产 学研结合, 共同为科研做出贡献。

\section{6. 结语}

中国科研院所的科研管理工作是一项复杂的系统工 程, 不仅需要科研管理人员的专业能力和服务意识, 还需 要合理可行的科研管理制度保障, 这样才能使科学研究更 加有效地规避风险。科研院所的科研管理工作对科研项目 申报、研究起着举足轻重的作用, 笔者在工作中体会到如 果想要达到一种好的管理方式, 可能最亟需的是建立科研 院所的科研管理系统, 将制度融入于系统中, 这样才能够 有章可循, 更好的促进科研管理水平的提高。相信在合理 的制度保障和科研管理者、科研工作者的共同努力下, 中 国科研院所的发展会越来越好。

\section{参考文献}

[1] 郁惠. 关于科研院所科研管理过程的问题探析 [J]. 经济研 究导刊, $2014(3): 197,208$ 。

[2] 于向海. 高校科研管理工作的几点思考 $[\mathrm{J}]$. 教育论坛, $2014(3): 9-10$ 。

[3] 陈以博, 陈伟民, 孟毅, 王守红. 加强地市级农科院所科研 管理工作的思考 [J]. 农业科技管理, 2014(2) : 36-38。

[4] 赵晓菊. 高校教师科研管理存在的问题及对策研究 [J]. 神 州教育, 20。

[5] 徐正富. 科研院所科研创新团队建设的思考 [J]. 管理创新, $2013(6)$ : 49-53。

[6] 张韩飞. 高校科研管理机制研究 [J]. 太原城市职业技术学 院学报, 2014(10) : 102-103。

[7] 王志刚, 张晓妮, 王国辉. 对提升高校科研管理水平的几点 思考 [J].农业科技管理，2013(2) :66-69。

[8] 韩国元, 尤琪. 科研院所科技管理能力研究 [J]. 管理世界公共管理, 2015 (2) : 104-105。

[9] 杨文艳, 李博欣, 孙洪范. 科研院所科研管理创新的思考 [J]. 中华医学科研管理杂志, 2006 (12) :339-341。

[10］李尚民, 窦新红, 童海兵. 地方农业科研院所创新科研管理 的思路探讨 [J].农业科技管理，2015(2) :28-30。

[11] 赵跃华. 高校科研管理制度比较研究及导向思考 $[J]$. 科学 管理研究, $2010(2): 30-33$ 。

[12] 王文娟, 张开春, 陈梅香, 徐秋红, 彭义杰. 关于农业科研 单位加强科研管理的分析与思考 $[\mathrm{J}]$. 农业科技管理, 2011 (10): 28-30。 